\title{
8 \\ Seoul City's Social Innovation Strategy: New Models of Communication to Strengthen Citizen Engagement
}

Jungwon Kim, Sojung Rim, Sunkyung Han and Ahyoung Park

\section{Introduction}

Social innovation is attracting considerable interest from public policy makers all around the world and South Korea is no exception. Since October 2011, when a well-known civil society leader, Wonsoon Park, became mayor, Seoul City has been going through rapid change. Led by the mayor on a mission to bring about change from the ground up, Seoul Metropolitan Government (SMG) has embraced citizen engagement and open dialogue in its policy-making processes.

One of the core mechanisms SMG has used to embed openness in the city's administration and to enable citizen participation is new models of communication, both online and offline. This chapter examines whether and how SMG's multi-channel communication has strengthened citizen engagement in Seoul. It aims to answer the following questions:

- How has SMG's multi-channel communication strategy helped foster citizen engagement?

- Has citizen engagement been strengthened by SMG's multi-channel communication approach and has this supported and sustained social innovation in Seoul?

- What challenges did SMG's use of multi-channel communication to strengthen citizen engagement face?

This chapter draws together information and insights from various reports, academic literature and public data on Seoul City's social innovation and citizen communication agenda. Eleven in-depth interviews 
were conducted with city officers in key departments to examine the new multi-channel communication tools introduced by SMG. The first part of this chapter introduces the 'social innovation mayor' in Seoul and places his social innovation plans in the South Korean context. Definitions of social innovation and citizen engagement employed within SMG are then provided. This is followed by an overview of SMG's citizen engagement strategy and an introduction to its major communication tools and programmes. The chapter then explores a case study that shows how multi-channel communication tools were employed to solve a specific social problem. The chapter concludes with a discussion of the challenges faced by SMG in using these new communication channels.

\section{The 'Social Innovation Mayor'}

When Wonsoon Park took office as the Mayor of Seoul City, many regarded him as the 'social innovation mayor'. While previous mayors had mainly focused on leaving a physical legacy after their mayoral terms, for example, by removing local street vendors and commissioning various landmark construction projects, Mayor Park declared that his legacy for Seoul City would be different. He would not leave behind a 'physical' legacy (Ryu and Kwon, 2014) but rather focus on changing the culture and the relationship between SMG and Seoul City's citizens.

Mayor Park had no previous experience in politics before running as the independent candidate in the mayoral by-election in $2011 .{ }^{1}$ Park's election slogan in 2011 was to become 'the mayor who changes the everyday lives of citizens'. He declared, 'citizens are mayors' and encouraged citizen engagement as a principle, underpinning the work of the new city administration. Mayor Park's philosophy and practice of listening to and acting on citizens' concerns was evident from early on in his election campaign. He met and talked with citizens on the street $^{2}$ and used various social media tools to communicate and listen to the needs of voters. His election campaign team was able to raise 3.9 billion won (US\$ 3.3 million) just three days into his official campaign, fundraising mainly through small donations made online from 5,778 supporters, who were mobilised through Twitter and Facebook (Seok, 2011).

During his first term between 2011 and 2014, Mayor Park led SMG to use many of the communication tools introduced in this chapter and to 'listen until citizens open their hearts'. His core philosophy and strategy during this period aimed at closing the distance between politics and 
citizens' everyday lives, giving citizens the confidence to voice their concerns and needs (Yoon, 2014). Throughout his term, Mayor Park was committed to making Seoul City a more 'liveable' human-centred city by restoring a sense of local well-being in communities (SMG, 2013d). He also envisioned Seoul City as a 'platform for collaboration and sharing', opening up and sharing the city's underutilised spaces, information and data with its citizens (Park, 2014). Park's vision and action gained support from citizens, especially the young, which led to a landslide victory for the Mayor for his second term. ${ }^{3}$

Many Koreans found Mayor Park's human-centred approach to city planning and design refreshing. South Korea is well known for its remarkable economic growth. In the aftermath of the Korean War, the country transformed itself from one of the poorest in Asia to one of the wealthiest countries in the world. ${ }^{4}$ Yet these rapid changes came at a cost. The decades of economic growth came about under authoritarian governments, which encouraged the growth of family-owned business conglomerates, known as 'chaebol', but stifled the vitality and diversity of civil society. The strong focus on materialistic abundance and hypercompetition, as well as rapid urbanisation, contributed to the breakdown of family and community relationships that were previously the safety net of traditional Korean society (Noland, 2014). South Korea has experienced growing income inequality (Oh, 2014). Among OECD countries, it has one of the highest suicide rates and one of the highest average numbers of hours worked annually per worker (OECD, 2014). South Korea also has the unhappiest children in the world (Phillips, 2013). Mayor Park's human-centred approaches were an attempt to restore social capital that was lost or forgotten during the fifty years of relentless economic growth. Cynics may view Park's citizen-focused strategy merely as a vote-winning tactic or a PR stunt. However, by translating the rhetoric into real action and change, new possibilities emerged.

\section{SMG's definitions of social innovation and citizen engagement}

The term 'social innovation' has been widely used in many different ways (Kim and Han, 2011). This study follows the definition introduced by The Young Foundation (2012). The main reason for following this definition is that it brings together the perspectives of both social innovation practitioners and academic researchers. As this study is focused on analysing a real case and aims to ensure that the lessons and conclusions 
are useful for practitioners and municipal administrations, it avoids a definition that is specific to certain academic subjects or fields.

The Young Foundation (2012) defines 'social innovation' as 'new solutions (products, services, models, markets, processes, etc.) that simultaneously meet a social need (more effectively than existing solutions) and lead to new or improved capabilities and relationships and better use of assets and resources. In other words, social innovations are both good for society and enhance society's capacity to act'. Within this definition, The Young Foundation (2012) suggests five core elements that need to be present in social innovation practices. These are: novelty; a focus on moving from ideas to implementation; a focus on meeting a social need; effectiveness; and evidence of enhancing society's capacity to act.

In comparison, SMG's definition of social innovation is much looser. SMG defined social innovation as 'a new way of solving social problems that either have been previously unsolved or have newly emerged' (SMG, 2013d, p. 305). This definition appears to focus on social problems (a deficit-based approach), rather than social needs (a less stigmatising approach) and capabilities (an asset-based approach). However, a study of SMG's practices and approaches (explored in the following sections) indicates that SMG in fact aimed to 'meet a social need' and to 'enhance society's capacity to act' by placing citizen engagement at the heart of SMG's strategy to catalyse social innovation.

SMG has developed new policies and solutions that meet social needs by listening to citizen voices directly through new models of communication. Furthermore, these approaches have forged new collaborations and interactions between citizens, civil servants and policy makers, going beyond usual working processes. In this way, SMG can be said to have enhanced society's capacity to act, empowering 'beneficiaries by creating new roles and relationships, developing assets and capabilities and/or better use of assets and resources' (The Young Foundation, 2012).

In the context of social innovation, citizen engagement is increasingly considered as the critical attribute that allows more diverse actors to be brought into the process of developing and then sustaining new answers to meeting social needs (Davies and Simon, 2013; Brodie et al., 2009). Westley argued that re-engaging populations and ideas that are excluded and disenfranchised from resources can enhance social innovation capacity and add to the resilience of the system in question (Westley, 2008). Citizen engagement is also important in identifying and better understanding social needs and challenges. Citizens have first-hand experience and tacit knowledge that is critical to the social innovation process (Davis et al., 2012). 
SMG regarded citizen engagement as one of the core strategies driving social innovation across Seoul. Citizen engagement was used as a mechanism that empowered Seoul citizens to express what they needed, explore how these needs could be met and decide what could be done in response. In this way, SMG was able to understand citizens' needs better, collect unexpected but working solutions, and create opportunities to resolve conflicting issues among different stakeholders (Y. Kim, 2013; T. Kim, 2013).

One way of conceptualising citizen engagement is to use the Spectrum of Public Participation developed by the International Association for Public Participation (IAP2, 2014). This sets out different public participation goals (from the perspective of the state) in order of increasing level of public impact, from 'inform' to 'consult', 'involve', 'collaborate' and finally, 'empower'. Prior to Mayor Park's administration, SMG used citizen engagement activities such as public hearings and citizen surveys to implement new city policies. However, these programmes were limited to the 'informing' and 'consulting' types of engagement. In contrast, many new tools and programmes developed and operated by SMG under Mayor Park's leadership specifically centred around 'involving', 'collaborating with' and 'empowering' citizens in decision-making activities. The next section will explore these tools and programmes together with the principles underpinning SMG's citizen engagement strategy.

\section{Citizen engagement strategy, principles and tools driven by SMG}

SMG is a large organisation, consisting of thirty departments and employing roughly 17,000 people (J. Ryu, 2013). The two departments primarily involved in developing and implementing social innovation activities were the Social Innovation Bureau (SIB) and the Public Communication Bureau (PCB) (Y. Kim, 2013; T. Kim, 2013). These two bureaus sat directly under the Mayor's Office, reflecting his determination to embed social innovation and citizen engagement as the core principles of city administration. While the SIB was set up to plan the city's social innovation strategy and support social innovation activities in Seoul, PCB was reorganised to develop ways in which citizens could be better engaged in the city's policy-making process. This chapter focuses primarily on the innovative communication strategy, principles and tools that were developed by the PCB to encourage citizen engagement.

The Mayor was a leading proponent of Seoul City's so-called 'Big Ear Policy', which put listening to citizens' voices at the heart of all the city 
administration's activities. The objective of these 'listening policies' was to enable citizens to express their own ideas and opinions, and to change the mindset of Seoul City officers to make them regard citizen voices as a valuable input for city policies.

Although the importance of citizen engagement in driving social innovation was recognised by the Mayor, it was difficult to shift the overall culture surrounding Seoul citizens and civil officers to embrace active and productive citizen engagement. Accepting diversity of ideas and viewpoints in the city administration was a new process for citizens as well as for the city government. Civil servants associated citizen voices with pickets, rallies and vigils and viewed them as an obstacle to their work. Citizens themselves had no experience of using other ways to make their voices heard. In the past, the process of receiving ideas and suggestions had been limited to only select groups of experts (J. Ryu, 2013; K. Ryu, 2013).

The Big Ear Policy aimed to build the foundations for initiating and fostering citizen engagement by breaking away from the entrenched culture within SMG. In order to reach the stage where citizens and SMG officers could develop innovative policies together, SMG initially focused on developing a new culture of citizen participation. It created symbols and spaces that reinforced the idea of a 'listening' culture. For instance, a large sculpture, the 'Big Ear', was installed outside the City Hall. When a person spoke into this object, his or her voice was recorded and broadcast live through speakers installed in the basement of the City Hall. Some messages were saved and passed to city officers for consideration. The Big Ear sculpture symbolised the city's commitment to listen to citizens more carefully and was one of many examples of attempts to create a listening culture within the city administration. ${ }^{5}$ A diverse range of tools, programmes, events, spaces, artefacts and banners were placed around Seoul to remind citizens of the Big Ear Policy. These were backed up with a series of opportunities for citizens to take part in engagement activities (see Tables 8.1 and 8.2).

To develop communication tools and programmes to implement the Big Ear Policy, the PCB, which was in charge of communication between SMG and Seoul citizens, defined three principles. These principles were set out to ensure that SMG's listening activities encouraged citizen engagement and the creation of policies that better met citizen needs. These three principles were: (1) an appreciation of two-way dialogue between SMG and Seoul citizens (in particular, this suggested a constant exchange of input and feedback between SMG and citizens, 
rather than seeing communication simply as one-time notifications); (2) making SMG's policy-making processes more transparent and opening up related information to citizens so that citizens could provide constructive input for the city's administration; and (3) sharing SMG's communication media with citizens (H. Kim, 2013; D. Kim, 2013). SMG encouraged citizens to express their opinions via its communication channels (including websites, radio stations, billboards and subway/ bus advertisement spaces), which were previously used exclusively to inform and promote SMG's work to citizens. In 2013, around 30\% of these media outlets could be used by citizens to promote their own social activities. ${ }^{6}$ There were also increased opportunities for citizens to contribute their own writing, photographs or videos on websites such as WOW Seoul and Seoul Talk Talk.

These three communication principles underpinned the implementation of new communication tools and programmes developed and operated primarily by the PCB. Two types of new communication channels - online and offline - were designed to serve different purposes.

The main goals of the online communication tools were to achieve real-time communication, fast responses and feedback, to reach out to diverse groups of citizens and to open up policy-making processes (see Table 8.1). Several online broadcasting channels showed live SMG meetings and events, and multiple social media tools were used to help engage and listen to citizen voices on a real-time basis (PCB, 2012; PCB, 2013).

Table 8.1 SMG's online communication tools

\begin{tabular}{|c|c|c|}
\hline Name & Description & Features \\
\hline $\begin{array}{l}\text { Hope Seoul } \\
\text { (www.seoul.go.kr) }\end{array}$ & $\begin{array}{l}\text { Official SMG } \\
\text { website }\end{array}$ & $\begin{array}{l}\text { 'Electronic Petition'; SMG } \\
\text { public data and meeting } \\
\text { minutes; participatory budget } \\
\text { programme reports; SMG } \\
\text { administration news. }\end{array}$ \\
\hline $\begin{array}{l}\text { WOW Seoul } \\
\text { (wow.seoul.go.kr) }\end{array}$ & $\begin{array}{l}\text { Website showing } \\
\text { User Created } \\
\text { Content (UCC) }\end{array}$ & $\begin{array}{l}\text { Video and photo sharing } \\
\text { platform and webtoon } \\
\text { (web+cartoon) services. }\end{array}$ \\
\hline $\begin{array}{l}\text { Live Seoul } \\
\text { (tv.seoul.go.kr) }\end{array}$ & $\begin{array}{l}\text { Online live } \\
\text { broadcasting } \\
\text { platform }\end{array}$ & $\begin{array}{l}\text { Real-time streaming of SMG } \\
\text { meetings and events, e.g., } \\
\text { Mayor Park's Seoul Story, } \\
\text { Cheong-Chek forums. Citizens } \\
\text { can add feedback. }\end{array}$ \\
\hline
\end{tabular}


Table 8.1 Continued

\begin{tabular}{|c|c|}
\hline $\begin{array}{l}\text { Seoul Talk Talk } \\
\text { (inews.seoul.go.kr) }\end{array}$ & Citizen news \\
\hline $\begin{array}{l}\text { Social Media } \\
\text { Center } \\
\text { (social.seoul.go.kr) }\end{array}$ & $\begin{array}{l}\text { Central location } \\
\text { for SMG social- } \\
\text { networking tools }\end{array}$ \\
\hline $\begin{array}{l}\text { Online Dasan Call } \\
\text { Center } \\
\text { (120dasan.seoul. } \\
\text { go.kr) }\end{array}$ & $\begin{array}{l}\text { Online citizen } \\
\text { petition platform }\end{array}$ \\
\hline
\end{tabular}

Online Mayor's Office (mayor.seoul.go.kr)

Ten Million Imagination Oasis (oasis.seoul.go.kr)

Seoul Smart Complaint Report App

\author{
Seoul Safety \\ Keeper App
}

Official website of Seoul city Mayor

Online platform for gathering policy ideas

Mobile application for processing citizen complaints
News on issues such as welfare, job openings and cultural events. Regularly publishes newsletters in which citizens create content as 'Citizen Reporters'.

Official social media platform integrating forty-four social media accounts run by various SMG departments.

The 120 Dasan Call Center is a 24-hour call centre that Seoul citizens can ask any question related to city life. The Online Dasan Call Centre is the extended online platform providing the same service.

Information on the Mayor's activities and core SMG policies, including the Mayor's personal blog, online channel streaming MMOs, the Mayor's daily schedule, and citizen feedback pages linked to various social media accounts.

Seoul citizens can post suggestions for policies. The process starts from ideation to policy adoption and promotes collective intelligence and communication among citizens, experts and public officials.

Citizens can report complaints on public facilities, traffic, environment and many more by using the web and mobile application. Users can upload text complaints with photo and geographic information, and also track SMG's responses to their complaints.

Mobile app for reporting disasters such as heavy rain, storms, heavy snowfalls, etc., with photos and geographic information. 
Meanwhile, SMG's offline communication activities typically involved discussions with different stakeholders in order to better understand complex issues and build consensus among diverse citizen groups with conflicting opinions. The range of offline communication activities used is summarised in Table 8.2.

Figure 8.1 illustrates the range of online and offline communication tools typically used at different stages of policy making, from problem identification and agenda setting to policy formulation, selection and approval. However, it is important to note that not all communication tools were used chronologically to develop each policy, nor did SMG's policy-making process follow a structured linear path. The early stages of the policy-making process featured SMG's multi-channel communication tools including the Cheong-Chek Forum (CCF), Suk-Ui, the Mobile Mayoral Office (MMO) and social media platforms. Social media was used continuously throughout the entire process (including implementation and evaluation stages), so that citizens could receive information about ongoing progress and give real-time feedback and comments.

Table 8.2 SMG's offline communication tools

\begin{tabular}{|c|c|}
\hline Tools & Description \\
\hline $\begin{array}{l}\text { Cheong-Chek (Policy by Listening) } \\
\text { Forum (CCF) }\end{array}$ & $\begin{array}{l}\text { Town hall meeting designed to develop new } \\
\text { policies or programmes }\end{array}$ \\
\hline Suk-Ui (Deliberation) & Meeting to formulate and approve policies \\
\hline Honorary Deputy Mayor & $\begin{array}{l}\text { Following Mayor Park's slogan, 'The citizens are } \\
\text { the Mayor', citizens act as an honorary deputy } \\
\text { Mayor for a year }\end{array}$ \\
\hline One Day Honorary Mayor & $\begin{array}{l}\text { Citizens from a variety of fields become } \\
\text { honorary Mayor for a day }\end{array}$ \\
\hline Citizen Speakers' Corner & $\begin{array}{l}\text { Speech podium located at Seoul City Hall, } \\
\text { based on Speakers' Corner at Hyde Park in } \\
\text { London }\end{array}$ \\
\hline Mobile Mayoral Office (MMO) & $\begin{array}{l}\text { The Mayor, SMG directors and managers } \\
\text { visit places and listen to citizen voices }\end{array}$ \\
\hline Policy Expo & $\begin{array}{l}\text { Annual event promoting citizen participation } \\
\text { in policy-making processes }\end{array}$ \\
\hline Seoul Citizen Hall & $\begin{array}{l}\text { Public space located at the basement of the } \\
\text { Seoul City Hall }\end{array}$ \\
\hline
\end{tabular}

Source: Authors' compilation. 


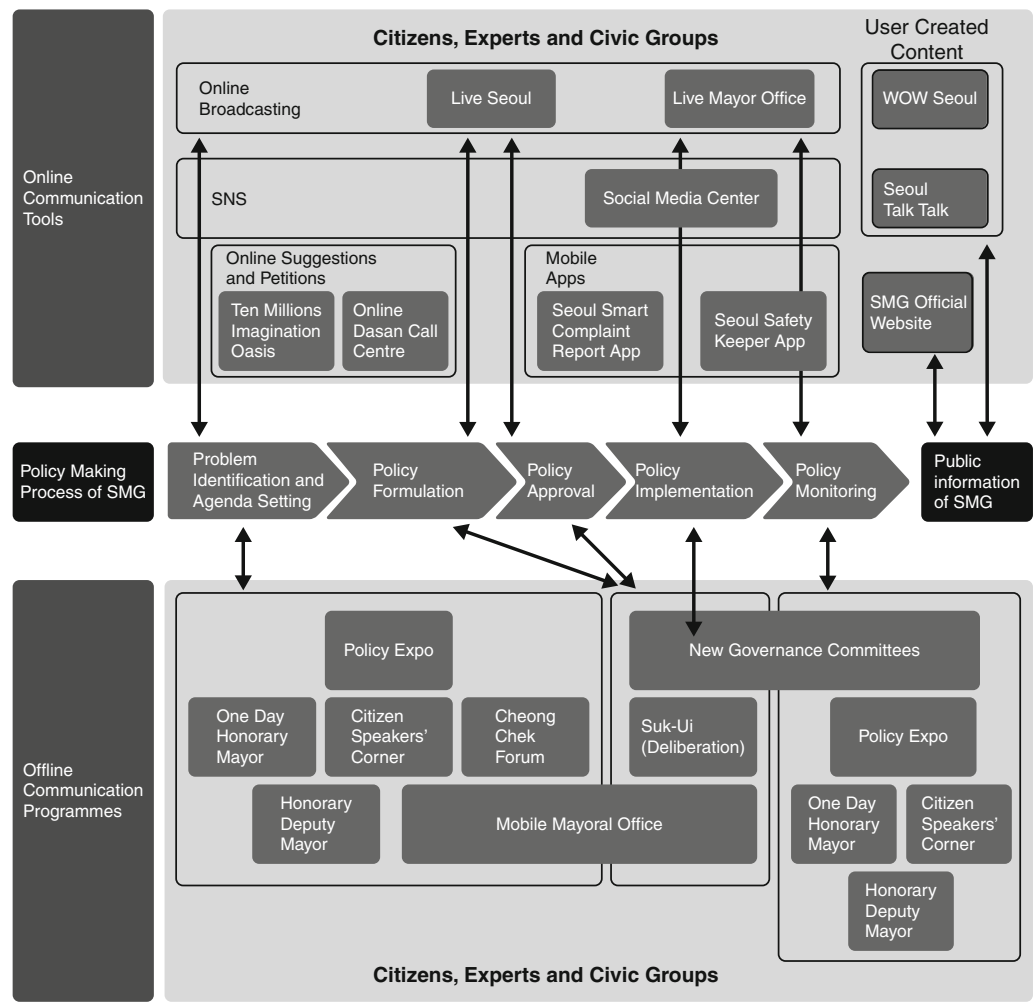

Figure 8.1 Overview of SMG online and offline communication tools and programmes

Source: Drawn by the authors.

\section{Three tools for engagement and communication}

This section introduces three major communication tools and programmes used by SMG.

\section{The Social Media Centre (SMC)}

SMG started its blog service in 2008, and since then, it has actively used social media tools - such as Twitter, Facebook and MeToday ${ }^{7}-$ to communicate with citizens. SMG also set up several websites to inform citizens of the activities it was undertaking. Under the so-called 'SNS administration' communication approach, SMG provided interactive information to citizens in real time and encouraged citizens to add and share content (J. Kim, 2013; SMG, 2013a). 
The Social Media Centre (SMC) took on the responsibility of centralising and coordinating information sent by citizens through diverse routes, ensuring quicker and more efficient communication. The SMC automatically gathered all messages received through SMG's forty-four social media accounts. ${ }^{8}$ It operated as a centralised system channelling relevant messages to appropriate teams, receiving feedback from those teams and sending feedback to the public through various accounts owned by the relevant teams and the Mayor. With this centralised approach, SMG was able to handle the large volume of citizen messages received through its social media accounts. Mayor Park's personal Twitter and Facebook accounts functioned as the most important direct communication channels between the Mayor and the citizens of Seoul. Between January and October 2012, a total of 29,976 suggestions (an average of 105 suggestions per day) were made to the Mayor through his social media accounts. Using a centralised system significantly reduced message processing time and enabled SMG to handle more citizen suggestions per day. Between November 2012 and March 2013 , a total of 18,807 messages were received, and on average 125 messages were processed per day, an increase of twenty messages per day compared with the period January to October 2012 (J. Kim, 2013; SMG, 2013a).

The SMC was particularly useful when unforeseen disasters or emergency situations occurred, as it enabled SMG to send out urgent messages through its many accounts at the same time. For instance, when Seoul's public bus system was affected by strikes, Seoul citizens were informed of alternative routes on a real-time basis (C. Kim, 2012; SMG, 2013c). Citizen comments passed to the SMC covered a broad range of issues, from small problems that could be fixed quickly to long-standing issues requiring innovative solutions. Social media communication was also helpful in gathering citizen feedback on pilot services. For instance, when Seoul City announced new night bus routes through its Facebook account, an instant online debate started, with 3,000 replies and 50,000 'likes' (SMG, 2013c). Citizens' comments were reviewed when nine new night bus routes were changed.

\section{The Cheong-Chek (Policy by Listening) Forum}

The Cheong-Chek Forum (CCF), a town hall meeting, has become a core part of Seoul City's policy development process (H. Kim, 2013; K. Ryu, 2013; J. Ryu, 2013). Cheong-Chek was a new word made by combining two Korean words 'listening' and 'policy'. By engaging with citizens through these forums, SMG aimed to understand local needs, find 
better ways to handle these issues and understand the views of the main beneficiaries of a policy.

In the past, consultation meetings with citizens had been carried out at the final stages of the policy-making process, where additional comments and suggestions from citizens made little or no difference to the major direction or content of a new policy (K. Ryu, 2013; J. Ryu, 2013). In contrast, CCFs took place at the early stages of the policy-making process and provided a space for citizens to propose and suggest new ideas, giving them more influence in terms of setting the agenda and making decisions. This was an innovative approach for Korean public administration, which had often regarded citizen engagement in a perfunctory manner (K. Ryu, 2013).

After the first forum was held in November 2011, CCFs took place on average once a week. The subjects discussed ranged from the local economy, education, welfare, homelessness and health to other issues that affect the daily lives of citizens. The topics for these forums were determined by reviewing diverse citizen opinions collected from multicommunication channels. After the review, the Attentive Listening Team within the PCB - which was in charge of running the CCFs - selected a subject for discussion and contacted relevant civic groups and experts working in the field. The team held several meetings with different groups to discuss the agenda and format of the CCF and whom to invite.

The CCFs were open to every citizen, but motivating citizens to participate was hard work. The Attentive Listening Team put substantial effort into advertising them through various online communication channels and also directly invited relevant groups of citizens. The entire process was broadcast live through the 'Live Seoul' site, SMG's Twitter account and Facebook page. A CCF usually lasted for 100 minutes and could be run in various formats, such as World Café or TED-style presentations followed by a question-and-answer session. The Mayor typically sat with the citizens, listening to their ideas and suggestions and sharing his thoughts at the end of each CCF. When each forum finished, the Attentive Listening Team compiled the suggestions made from the CCF and established an action committee comprised of city officers in relevant departments, representatives from civic groups and other experts. This committee continued to hold official discussions until the suggestions made by citizens were implemented. Usually it took between two months and a year for suggestions to be realised. During this period of time, SMG officers published a progress report every two weeks on the CCF website and shared updates with CCF participants through a text messaging service. 
Between November 2011 and November 2012, forty-one CCFs were held, with a total of 5,456 citizens in attendance. The forty-one forums produced 717 citizen suggestions and 538 suggestions (75\%) were subsequently implemented. The remaining 166 suggestions were to be included in SMG's long-term plans. The 717 suggestions can be categorised into three groups: development of new programmes (84.1\%); improvement of existing systems such as youth employment and homelessness policies (13\%); and allocation of new budgets (2.9\%).

A key outcome of the CCF after its first year of operation was the creation of new public-citizen governance bodies that aimed to develop and support public policies. One of the biggest tasks was to report on the progress being made while SMG implemented the citizen proposals made at the CCF. This required SMG to set up public-civic groups to gather feedback and to ask these bodies to take some responsibility in implementing citizen ideas. One example of a programme implemented as a result of the CCF is the Seoul Library Network, which was created after discussing new policies supporting libraries in Seoul.

\section{The Mobile Mayoral Office}

The Mobile Mayoral Office (MMO) was designed to identify the root causes of unresolved issues or hidden problems and suggest possible solutions. To achieve this goal, key decision-makers, including the Mayor, two deputy Mayors, the head of a borough, Members of Parliament, and city and local councillors, visited local sites where there were long-standing issues and met residents affected by those issues. The MMO employed multi-channel communication tools (the CCF, $S u k-U i$ and other online communication tools) during the course of its operation.

SMG ran two types of MMO: an MMO for boroughs in Seoul and an MMO for selected issues. ${ }^{9}$ Borough-level MMOs took place regularly while MMOs for selected issues only took place when a certain issue became pressing.

Borough-level MMOs typically ran for two days. A preparation team, which usually consisted of officers from the Local Authority Team at SMG and from a borough office, selected ten major issues within the borough. The team also set out a visiting plan and arranged citizen meetings. The MMO started with a briefing for decision-makers on the issues, followed by visits to key places and meetings with local representatives. During the first day, key decision-makers and their working teams often came across new issues that they felt should be added to the list of critical issues to be discussed. In the evening of the same day, key 
decision-makers and their working teams had an internal meeting to review what they had experienced and heard during the day. Their discussion typically ended with some conclusions on immediate actions, mid to long-term plans and who should be assigned ownership of these actions and plans. On the second day, the Mayor presented the suggestions agreed from the previous night's meeting and followed this with an open town hall meeting with citizens. The whole process was broadcast through the 'Live Mobile Mayoral Office' 10 website and reported live on Twitter and Facebook. As a final step, a new governance committee was set up to monitor and discuss agreed actions after the completion of the MMO. The committee members included the directors of the Local Authority Team in SMG, managers of relevant SMG teams, directors of relevant borough divisions and citizen representatives.

The second type of MMO was run to solve specific high-profile issues. For instance, in 2013, SMG ran an MMO to invigorate traditional markets, which were rapidly losing their customer base to big supermarket chains. This MMO lasted for four days and included visiting four traditional markets and having various citizen meetings including a Cheong-Chek Forum. The committee continued to monitor whether the action items that came out of the process were implemented.

Between 2012 and 2014, Seoul City organised nineteen MMOs. SMG's Local Authority Team summarised four key outcomes: providing solutions to collective petitions or problems causing serious conflict among diverse stakeholders; setting out next steps and clear directions for projects under long-standing review; solving unexpected problems and providing additional resources and clear decisions for prolonged projects; and offering an opportunity for close collaboration between SMG and local boroughs. The more detailed outcomes of an MMO are discussed in the next section through a case study.

\section{Case study: unsold apartments in EunPyeong Newtown}

The unsold apartments in the EunPyeong New Town development had been a long-standing problem for Seoul City's administration that put a significant burden on city finances (SH Corporation, 2013). The SH Corporation, the public housing company owned by SMG, had 618 unsold apartments remaining at EunPyeong New Town three years after the completion of the apartment buildings (SMG, 2012). These unsold apartments were worth around 493 billion won (US\$ 467 million), and it was crucial to sell them to address one of the biggest problems faced by SMG - a large amount of debt. ${ }^{11}$ Local residents were also 
concerned about security, as a large number of apartments had been left empty for more than four years (Song, 2013). However, in January 2013, SMG announced that all 618 apartments were to be sold, within seventeen days of establishing a task force to address this problem (SH Corporation, 2013). This case study examines how SMG's various forms of communication made this possible.

SMG's overall communication strategy helped it to identify invisible and unexpected needs and to understand the nature of these needs. When the Mayor heard about the EunPyeong New Town problem, he wanted to understand the nature of this problem, analyse why these apartments had failed to attract buyers in Seoul and find a way to sell them. He asked his team to relocate his office to one of the unsold apartments and stayed there with SMG officers for ten days, listening to residents and identifying their needs (Song, 2013; J.E. Lee, 2013; Hwang, 2013). From this first MMO, SMG and SH Corporation started to discover hidden problems and get more insight into the severity of known problems. Residents' major complaints concerned infrastructure problems such as a shortage of nurseries, libraries and public transportation, and complaints about the existence of an army base near the complex. Through mechanisms such as the Cheong-Chek Forum and social media platforms, residents made a total of 146 suggestions to rectify these issues (MMO, 2012; SH Corporation, 2013). SMG and SH corporation made new attempts to attract homebuyers based on residents' suggestions. All key decision-makers visited the site to understand firsthand citizens' concerns.

SMG was then able to create innovative solutions through diverse types of collaboration. All of the people interviewed for this chapter repeatedly commented that the creation of new types of collaboration had been a key outcome of SMG's communication approach (J. Ryu, 2013; Hwang, 2013; J.E. Lee, 2013; K. Ryu, 2013). New forms of collaboration were made between SMG and other civic groups - including individual citizens - and between SMG and other public parties such as boroughs, councillors, MPs and other public organisations. This was because SMG's communication strategy aimed to strengthen citizen engagement; the end results of various communications were, therefore, the creation of policies or programmes that implemented citizens' proposals. To achieve this, SMG had to collaborate with actors that had close relationships with citizens.

In the case of EunPyeong, these new forms of collaboration were crucial in solving the problem of unsold apartments. By inviting a range of key decision-makers from a number of departments into the same space, 
silos that existed between departments and organisations were removed and a new way of thinking started. The power of the EunPyeong case lay in creating a space for key decision-makers to gather in one place to work together within a limited period of time. Furthermore, the limited time frame intensified the pressure on decision-makers and their working teams to compromise on difficult areas of dispute and find shared solutions. The fact that they were making a promise to the citizens faceto-face (rather than announcing it on a webpage) added weight to the commitment they were making (J.E. Lee, 2013; J.S. Lee, 2013; Hwang, 2013; K. Kim, 2013). Solutions suggested were reviewed within 24 hours by the public through a Cheong-Chek Forum and various social media platforms, including live Internet broadcasting.

The open and participatory nature of SMG's communication approach helped to provide legitimacy to its new policy decisions. The people interviewed for this chapter, mainly SMG officers, reported that Seoul citizens, especially those living in deprived and underserved areas, felt that their voices were being properly heard by the authorities for the first time (J. Ryu, 2013; K. Ryu, 2013; Hwang, 2013). According to SMG, citizens started to trust civil servants and this, in turn, led them to cooperate with SMG and accept its suggestions, even if they were unpopular. Interviewees also commented that opportunities to watch the Mayor's face-to-face promises at a CCF or live broadcast, and the Mayor's personal briefings via SNS, contributed to growing trust among citizens. One interviewee explained that:

The ultimate goal of public administration is efficient and effective delivery of public services. In this sense, SMG's new communication exercising openness and citizen engagement has certainly contributed to the achievement of such a goal. Whereas communication with citizens might have delayed the whole process of SMG's administration, it offered the most valuable opportunity for SMG to gather very different, sometimes conflicting and contrasting, opinions among citizens and let citizens and SMG express their thoughts openly and come up with agreeable new solutions. By doing so, citizens could accept SMG's decisions and enjoyed the public services delivered by SMG. (J. Ryu, 2013)

\section{Challenges}

SMG's new communication strategy has faced several challenges. First, it became clear that new communication tools and programmes - 
including online and offline channels - did not guarantee access to a wide range of people's voices. Given the high usage rate of the Internet and smart phones in Seoul, ${ }^{12}$ SMG's online communication tools certainly increased its opportunities to listen to citizens' views. However, the main groups who actively used these tools to express their views were younger generations or certain outspoken groups. Offline communication activities mainly attracted citizens who were already active participants in public discourses or had close relationships with civic groups invited to a CCF or MMO.

Second, the new communication tools and programmes contributed to solving only a limited range of problems. Each communication channel had strong features that helped to solve certain issues. However, it was not clear that these new channels were good at handling all types of social issues.

Third, new communication tools and programmes required larger resources to operate and it was hard to provide sufficient resources under conditions of public sector austerity. This was particularly true for offline programmes, because most of these led to ongoing conversations within committees that lasted until ideas and solutions were realised. This follow-up procedure ${ }^{13}$ demanded almost one full-time SMG officer to resource it (K. Ryu, 2013; K. Kim, 2013). However, this was a new type of role within SMG and the scale of SMG's debt made it hard to recruit new staff.

Fourth, trust between SMG, civic groups and individual citizens was required to obtain positive results from citizen engagement. Although distrust between SMG, civic groups and individual citizens had started to diminish, there had not previously been many opportunities for professionals in different sectors to co-create successful solutions together. The new communication channels brought a shift towards a collaborative culture based on stronger bonds of trust between different sectors. However, many interviewees felt that SMG needed to continue to strengthen trust and bonding relationships with civil society and individual citizens.

Finally, strong leadership was required to make new communication work. The core principles of SMG's new communication strategy were dialogue, openness and sharing. These principles required SMG to give up some of its power, focus more effort on citizen engagement and be monitored by over 10 million Seoul citizens at any time. On the surface, these requirements imposed extra burdens on SMG officers. Under these circumstances, the power of a strong leader who truly understood these principles and was able to communicate them cannot 
be underestimated. Such strong leadership was needed to positively influence not only SMG officers but also many different stakeholders outside SMG. This study has observed Mayor Park's strong leadership and its impact on the success of the EunPyung case using an MMO. However, this in itself became a challenging point since strong leadership meant that new communication models greatly depended on one individual. Interviewees felt that SMG needed to build a system and a culture to sustain and stabilise new communication tools and programmes fostering citizen engagement.

\section{Conclusion}

This chapter has examined the link between citizen engagement and social innovation in the context of Seoul City. SMG was going through a rapid change in the way it worked with citizens under the leadership of Mayor Wonsoon Park. The motto 'citizens are mayors' was embedded in the new models of communication and citizen engagement was seen as one of the core elements that could catalyse social innovation.

SMG was starting to understand that citizens were 'experts in their own lives' (The Young Foundation, 2012) and that citizen involvement in the policy-making process helped to draw out social needs and identify potential solutions (Bason, 2010). In particular, the EunPyeoung Mobile Mayoral Office showed that bringing together key decision-makers with residents brought about deeper insights into the problem at hand. Furthermore, this type of engagement forged new collaborations and interactions between citizens, civil servants and policy makers, going beyond usual working partners, 'creating new roles and relationships, developing assets and capabilities' and 'better using assets and resources' (The Young Foundation, 2012), thereby enhancing society's resilience and capacity to act.

There were challenges to SMG's citizen engagement and communication strategies. Due to the nature of the tools, there may have been limited representation of diverse voices. These tools may have been adequate for only a limited range of problems and were resource-intensive to administer. There was a need to ensure that long-term sustainability of these engagement approaches did not depend on one leader. Perhaps the biggest challenge lay in encouraging trust between citizens, public officers, civic groups and experts to work together and co-create new solutions. Past experiences led many South Koreans to think that citizen engagement processes were a waste of time and this created a sense of apathy towards citizen engagement activities. 
Nevertheless, Seoul City was attempting to build the confidence of its citizens by providing them with new - positive - experiences of engagement. SMG's multi-channel communication approach offers valuable lessons to other cities that are ambitiously planning to initiate and drive social innovation.

\section{Notes}

Spreadi (www.spreadi.org), for further information, contact: jungwon@spreadi. org or sojung@spreadi.org.

1. Prior to the election in 2011, Mayor Park was a human rights lawyer and social justice activist and founder of the non-profit watchdog organisation People's Solidarity for Participatory Democracy; the Beautiful Foundation and the Beautiful Store, Oxfam-inspired models aimed at growing culture of giving; and the Hope Institute, a social innovation think and do tank.

2. For the 2014 election campaign for his second-term mayorship, Mayor Park carried a GPS tracker in his rucksack, so that citizens could track his whereabouts by using 'findwonsoon' webpage and find him to have a conversation with him. The campaign camp, which was called 'honeybee camp', had a non-hierarchical structure and was open to citizens who wanted to use the space (Chosun Biz, 2014).

3. In 2014, Wonsoon Park won $56.12 \%$ of the 4.9 million votes cast (National Election Commission, 2014).

4. South Korea's GNI per capita rose from to $\$ 110$ in 1962 to $\$ 25,920$ in 2013. GNI per capita (formerly GNP per capita) is the gross national income, converted to US dollars using the World Bank Atlas method, divided by the midyear population (World DataBank, 2014).

5. Another good example is the Citizen Hall. The basement areas of the Seoul City Hall covering two floors, named as the 'Citizen Hall', were provided for citizens' use. The Citizen Hall had an exhibition hall, gallery space, open lounge, event space available for hire, café and more. These efforts were made with the goal of enabling citizens to feel ownership of the City Hall.

6. Seoul-based social enterprises have used this media to advertise their products or programmes, supported by donations from major advertisement agencies. Around 60 enterprises benefited from this scheme between January and July 2013 (PCB, 2013).

7. MeToday (me2day.net) is a popular Korean social media platform, similar to Twitter, run by Korean company Naver.

8. SMG runs thirty-three Twitter accounts, six Facebook accounts, four MeToday accounts and two blogs. The Mayor uses his own Twitter account, @wonsoonpark, with 736,519 followers and Facebook account, www.facebook.com/wonsoonpark, with 170,894 followers.

9. Seoul has twenty-five boroughs. However, their budgets are quite small and many hope to get some financial support from SMG to solve daily issues of Seoul citizens together. In order to provide a programme directly beneficial to citizens, SMG runs the MMO with each local borough.

10. www.seoul.go.kr/runningmayor/ 
11. The city's debts stood at 20 trillion won (around US\$ 19 billion) when Mr. Park was elected as Mayor. The debt decreased to 18.861 trillion won (around US\$ 17.6 billion) at the end of May 2013 (SMG 2013b).

12. South Korean high-speed wireless Internet penetration rate reached $100.6 \%$ in 2012, according to the OECD (Moran, 2012).

13. These procedures include arranging committee meetings, providing feedback to committee members and citizens and coordinating them to agree on one finalised policy or programme (K. Ryu, 2013; Hwang, 2013; K. Kim, 2013).

\section{References}

Bason, C. (2010) Leading Public Sector Innovation: Co-Creating for a Better Society. Bristol: Policy Press.

Brodie, E., Cowling, E. and Nissen, N. (2009) Understanding Participation: A Literature Review. London: IVR, NCVO and Involve.

Chosun Biz (2014) 'There Were Wearable and Augmented Reality Apps Behind Won-soon Park's Reelection' Chosun Biz. Available from http://goo.gl/p1EgJc [Accessed 22 September 2014. In Korean].

Davies, A. and Simon, J. (2013) The Value and Role of Citizen Engagement in Social Innovation. A deliverable of the project: 'The theoretical, empirical and policy foundation for building social innovation in Europe' (TEPSIE). Brussels: European Commission, DG Research.

Davies, A., Simon, J., Patrick, R. and Norman, W. (2012) Mapping Citizen Engagement in the Process of Social Innovation. A deliverable of the project: 'The theoretical, empirical and policy foundation for building social innovation in Europe' (TEPSIE). Brussels: European Commission, DG Research.

Hwang, I. (2013) Interview with Hwang, InSik (Director of Local Autonomy Adiministration Division, Seoul Metropolitan Government).

IAP2 (2014) IAP2 Spectrum of Public Participation. Available at http://goo.gl/ dveiVR [Accessed 15 September 2014].

Kim, C. (2012) Social Media Administration of the Seoul City. Available at http:// www.bloter.net/archives/133994 [Accessed 15 September 2014. In Korean].

Kim, D. (2013) Interview with Kim, DongKyung (Campaign Director, Public Communication Bureau).

Kim, H. (2013) Interview with Kim, HyunSung (Media Advisor of Seoul Metropolitan Government).

Kim, J. (2013) 'Listening to Citizen Opinions Using Social Media: The Case of Social Media Center at Seoul Metropolitan Government'. In Seoul 2013 SNS Conference, pp. 41-55 [In Korean].

Kim, K. (2013) Interview with Kim, KwonKi (Team Leader of Local Authority Administration Division, Seoul Metropolitan Government).

Kim, T. (2013) Interview with Kim, TaeGyun (Team Leader of Social Innovation Division, Seoul Innovation Bureau, Seoul Metropolitan Government).

Kim, Y. (2013) Interview with Kim, Y. (Social Innovation Advisor, Seoul Metropolitan Government).

Kim, J. and Han, S. (2011) 'A Guided Tour of Social Innovation in Korea'. Hope Institute. Available at http://goo.gl/OAMMn3 [Accessed 19 September 2014]. 
Lee, J.E. (2013) Interview with Lee, JongEon (Chief of Marketing Division, SH Corporation).

Lee, J.S. (2013) Interview with Lee, JongSun (Manager of Public Relations, SH Corportation).

MMO (2012) 'There is an answer at the on-site'. Mobile Mayoral Office, S.M.G. (Presentation).

Moran, A. (2012) 'OECD: South Korea high-speed Internet penetration rate tops 100\%'. Digital Journal. Available at: http://digitaljournal.com/article/329199 [Accessed 22 October 2014].

National Election Commission (2014) Available at http://goo.gl/jFkG4R [Accessed 17 September 2014. In Korean].

Noland, M. (2014) 'Six Markets to Watch: South Korea'. Foreign Affairs. Available at http://goo.gl/6S6qWN [Aceessed 21 September 2014].

OECD (2014) OECD Stat Extracts. Available at http://stats.oecd.org/ [Accessed 22 October 2014].

Oh, K. (2014) 'Inequality threatens Korea's growth: Report'. The Korea Herald. Available at http://goo.gl/iPYb1K [Accessed 17 September 2014].

Park, W. (2014) 'Unusual Suspects Special: Seoul's Mayor Park Talks About Collaboration'. SIX (Social Innovation eXchange). Available at http://goo.gl/ WiZfjg [Accessed 10 September 2014].

PCB (2012) 2012 Annual Report of Public Communication Bureau. SMG: Public Communication Bureau [In Korean].

PCB (2013) 2013 Major Work Plan of the Public Communication Bureau. SMG: Public Communication Bureau [In Korean].

Phillips, M. (2013) 'Korea is the world's top producer of unhappy school children'. Quartz. Available at http://goo.gl/oBiurd [Accessed 17 September 2014].

Ryu, J. (2013) Interview with Ryu, J. (Team Leader of New Media Divison, Public Communication Bureau, Seoul Metroplitan Government).

Ryu, K. (2013) Interview with Ryu, KyungHee (Coordinator of Smart Work Committee).

Ryu, H. and Kwon, W. (2014) 'I don't want to leave anything as the Seoul Mayor'. Ohmynews. Available at http://goo.gl/kaW5Lz [Accessed 15 September 2014].

Seok, J. (2011) 'Park Won-soon reaches fundraising goal in 52 hours'. The Hankyoreh. Available at http://goo.gl/AoX5Pa [Accessed 22 September 2014].

SH Corporation (2013) EunPyung Newtown 3-RE Smart White Paper.

SMG (2012) 'Eunpyeong's worth is Geumpyeong [golden]'. Seoul Metropolitan Government. Available at: http://goo.gl/rvhjmV [Accessed 15 September 2014].

SMG (2013a) 2012 Seoul Citizen Communication White Paper. Seoul Metropolitan Government. [In Korean].

SMG (2013b) 'Seoul Metropolitan Government's debt on the decline since Mayor Park Won Soon's inauguration'. Seoul Metropolitan Government.

SMG (2013c) 'Communicate between citizens and the Seoul City through SNS'. Seoul Metropolitan Government. Available at http://goo.gl/tZMywb [Accessed 15 September 2014. In Korean].

SMG (2013d) 2012 Seoul City White Paper - 100 Policies. Seoul Metropolitan Government. [In Korean.]

Song, S. (2013) Interview with Song, SoonKi (Team Leader, Sales Team, Marketing Division, SH Corporation). 
The Young Foundation (2012) Social Innovation Overview - Part 1: Defining Social Innovation, A deliverable of the project: 'The theoretical, empirical and policy foundations for building social innovation in Europe' (TEPSIE). Brussels: European Commission, DG Research.

Westley, F. (2008) The Social Innovation Dynamic. Canada: Social Innovation Generation at the University of Waterloo. Available from http://goo.gl/ CdyGb2 [Accessed 15 September 2014].

World DataBank (2014) Available at http://goo.gl/Gmi9gI [Accessed 17 September 2014].

Yoon, S. (2014) 'Until citizens open their hearts'. Nocut news online. Available at http://goo.gl/XG2hqT [Accessed 15 September 2014].

(c) (i) Except where otherwise noted, this work is licensed under a a copy of this license, visit http://creativecommons.org/licenses/by/3.0/ 